Proceedings of the 2011 Winter Simulation Conference

S. Jain, R.R. Creasey, J. Himmelspach, K.P. White, and M. Fu, eds.

\title{
MODELING HUMAN BEHAVIOR IN CUSTOMER-BASED PROCESSES: THE USE OF SCENARIO-BASED SURVEYS
}

\author{
Alinda Kokkinou \\ NHTV Breda University of Applied Sciences \\ Sibeliuslaan 13 \\ 4837 CA Breda, THE NETHERLANDS
}

\author{
David A. Cranage \\ The Pennsylvania State University \\ 201 Mateer Building \\ University Park, PA 16802, USA
}

\begin{abstract}
Due to the complex and relatively unpredictable nature of human behavior, customer service-based processes such as those featured in call centers, restaurants, and hotels can be challenging to model. The present study provides an example of using established theories of customer behavior, in combination with primary data collection, in a time and cost efficient way to model customer decision-making in a particular situation. The context of the study is a hotel check-in process manned by three service employees to which management would like to add a self-service check-in alternative, in order to reduce waiting times. In order to model how customers choose between using the service employee and using the self-service technology, a crucial component of the simulation model, scenario-based surveys are used to supplement existing theories. The simulation study is briefly described and the advantages of this approach are discussed.
\end{abstract}

\section{INTRODUCTION}

Customer service-based processes such as those featured in call centers, restaurants, and hotels can be challenging to model for several reasons. First, human behavior may be unpredictable and complex (Tumay 1995). Understanding and modeling how individuals (customers and service providers) make decisions is therefore difficult (Sterman 1987). For example, in a waiting line situation, common to many customer service-based processes, customers facing similar conditions may behave differently with respect to balking, joining the line and waiting for their turn, or joining the line and subsequently reneging. Second, the direct customer contact that occurs in service-based processes results in processes that are not very well defined (Wemmerlöv 1990). In processes with high customer contact, customers are more likely to be involved in the process itself and thereby introduce variability in the duration, quality, and exact nature of the service (Chase 2010). This is especially true for customer service-based processes that allow for customization.

Modelers have several techniques at their disposal to overcome the difficulty of modeling human behavior. In smaller systems, modelers can gather primary data on individuals' decision-making processes using interviews, surveys, and participant observation (Sterman 1987). In larger, more complex systems, modelers can draw on previously tested theories to formulate the model, and conduct sensitivity analysis to examine the estimated parameters. Both approaches have advantages and limitations. Even though it may provide context specific and relevant information, primary data collection can be expensive and time consuming (Seawright and Sampson 2007, Sterman 1987). Conversely, established theories can be cheap and quick to access, but may not allow for accurate modeling as they may not be sufficiently context specific.

The present study provides an example of using established theories of how customers behave, in combination with primary data collection to model a customer service-centered process. We examine a 


\section{Kokkinou and Cranage}

hotel check-in process manned by three service employees to which management would like to add a selfservice check-in alternative. To correctly assess the impact of adding the self-service technology alternative and thus provide solid information for the business decision to be made, it was necessary to model customers' choice between the two service delivery alternatives. We used existing theories about how customers decide to choose between using a service employee and using the self-service alternative in combination with a scenario-based survey to model customers' decision between the two service alternatives.

The next section further describes the context of the study. Section three consists of a review of the literature on customer decision-making involving self-service technology. Section four describes the scenario-based survey, and section five briefly describes the simulation study. The final section summarizes the advantages and limitations of the approach presented.

\section{CONTEXT OF THE STUDY}

Hospitality firms are typically concerned with providing high quality service to their customer in a timely, yet cost-efficient manner. Consequently, waiting times and labor costs have been the performance measures of choice in the study of service systems such as fast food restaurants (Hueter and Swart 1998). By reducing waiting times, firms can improve customers' perceptions of service quality and satisfaction, and positively impact their future financial performance. By reducing operating costs, for example through improved labor scheduling, firms can also improve their financial performance. However, from a queuing theory perspective, waiting time and operating cost reduction are conflicting objectives that cannot be improved simultaneously (Dickson, Ford, and Laval 2005). What this implies is that, in order to improve waiting times, a costly increase in capacity is oftentimes needed. Conversely, a reduction in the number of service employees is typically accompanied by an increase in waiting times for customers. This is a challenge for hospitality firms, which are labor-intensive and where timeliness of the service is very important (Starks and Whyte 1998).

Recently, self-service service technologies have been proposed as a way to simultaneously reduce waiting times and operating costs (Weijters et al. 2007). Self-service technologies are technological interfaces that allow customers to produce a service themselves, without the assistance of a service employee (Meuter et al. 2000). Widely accepted self-service technologies include automated teller machines (ATMs), online banking, online brokerage services, retail self-check-outs, online retailers, and selfservice check-in kiosks at airports, hospitals and hotels. These self-service technologies are successful because they provide customers with more flexibility in when, and how they receive a service (Meuter et al. 2000). For example, using ATMs, customer can access their funds outside of the bank's normal operating hours. These self-service technologies also provide benefits to firms, including increased speed of delivery, precision, customization, reduced heterogeneity in the service encounter, and competitive differentation (Berry 1999; Curran, Meuter, and Surprenant 2003; Weijters et al. 2007).

One hotel customer service-based process that has received a lot of attention recently in both the academic and practitioner literature as being particularly well-suited to self-service technology is the checkin process (Mayock 2010, Oh and Jeong 2009). However, the assumption that the implementation of selfservice technology in the check-in process could simultaneously improve waiting times and decrease system operating costs has yet to be empirically tested. Hotel check-in is a relatively straightforward process as it has a high degree of routinization (Wemmerlöv 1990). Customers arrive in the hotel lobby and join the line(s) at the check-in desk to wait for service. After they have received service, which consists of a brief information exchange, they leave the service area. The introduction of self-service technology in the hotel check-in process would increase the complexity of this system, as customers would be able to choose between checking in using a self-service kiosk and using a service employee.

In order to examine whether the implementation of self-service technology in the check-in process could simultaneously improve waiting times and decrease system operating costs, it was necessary to accurately model customers' choice of whether to use self-service technology or use the service employee. In this particular simulation study, the model's results, and hence the business decision to be made were 


\section{Kokkinou and Cranage}

sensitive to variations in customer behavior. Specifically, the proportion of customers that chose to use the self-service technology impacted the waiting times for both service alternatives. Previous research had proposed and tested several models of how customers decide to use self-service technology that could be used in the context of a simulation model.

\section{LITERATURE REVIEW}

Using attitudinal research, previous research has formulated several models of how customers decide between using a service employee and using a self-service technology (Dabholkar and Bagozzi 2002). According to these models, customers' beliefs about the self-service technology drive their attitudes towards the self-service technology which in turn influence their decision to use it (Dabholkar 1994, Weijters et al 2007). For example, Weijters et al (2007) found that customers' beliefs about the usefulness, ease of use, reliability and fun of supermarket self-scanners were positively related to their attitudes towards the selfscanners, which in turn positively influenced their usage of the self-scanner. In addition to customer attitudes, previous research has also examined the role that customer characteristics such as self-efficacy, technology anxiety, and need for human interaction play in customers' decision to select the self-service alternative. Self-efficacy was shown to increase usage intentions (van Beuningen et al. 2009) while technology anxiety (Meuter et al. 2003) and need for interaction (Meuter et al. 2005) were shown to decrease usage intentions.

Despite the theoretical insights they provide in customers' decision-making processes, these models are of limited practical use from a simulation modeling perspective. First, while providing qualitative information about customers' decision-making processes with regards to using self-service technology, they do not provide the quantitative information necessary for simulation modeling. For example, Weijters et al. (2007) showed that a one point increase in customers' attitudes towards using a self-scanner when shopping in a supermarket meant the customers were 7.34 times as likely to use the self-scanners than without the increase. However, customers' attitudes were influenced by their beliefs about the self-service technology which encompassed many factors such as the belief that the self-service scanner would allow them to shop faster, would make them more efficient, and would be reliable. Due to the large quantity of variables, and complex relationships between them, it would be difficult to formulate a simulation model based on this model and subsequently estimate the parameters and conduct sensitivity analysis as suggested by Sterman (1987). The belief variables used in these models were therefore not actionable from a simulation modeling perspective.

Second, researchers have attempted to develop models that can be generalized to different self-service technologies and in different situations, and are therefore not context specific. For example, Curran and Meuter (2007) developed one model and tested it using three different self-service technologies, including ATMs, online banking, and bank by phone. However, these three self-service technologies have different benefits which influence their use. For example, customers using online banking do not experience the physical discomforts associated with waiting in a facility outside the home. Conversely, customers using an ATM may experience waiting within the facilities due to delays or queues (Baker and Cameron, 1996).

Several studies that included waiting time found it to have a significant effect on customers' decision to use self-service technology (Dabholkar 1996, Oh and Jeong 2009). Reductions in waiting time have been cited as drivers of satisfaction when using self-service technology (Meuter et al. 2000) and motivators to use self-service technology (Bateson 1985). Anticipated waiting time has been shown to influence customers' intentions to use the self-service technology (Dabholkar 1996, Oh and Jeong 2009). Anticipated waiting time is also one of the antecedents of perceived usefulness which has been shown to be a strong predictor of customers' attitudes towards self-service technology and intentions to use the selfservice technology (Weijters et al. 2007). Based on these findings, we hypothesized that, in contexts where waiting time may be a consideration for customers, waiting line length could be used to predict customers' choice of whether to use the self-service technology or use the service employee.

Since customers use their observed queue length along with their beliefs about processing times to form an estimate of the likely duration of their waiting time (Kumar, Kalwani, and Dada 1997), we used a 


\section{Kokkinou and Cranage}

scenario based survey to examine whether queue length could be used to predict customers' choice of which service alternative to use. From a simulation perspective, waiting line length is an actionable variable, since it can be incorporated in a decision rule.

\section{SCENARIO-BASED SURVEY}

In the context of self-service technology research, scenario-based surveys have been widely used as they allow researchers control over the experimental conditions and manipulated variables while reducing random noise (Bitner 1990, Dabholkar 1994, Weijters et al. 2007). Furthermore, the use of online survey tools allows for fast and cost-effective data collection. For example, for this particular study, surveymonkey, an online survey tool, was used to obtain 1,472 responses. More than $50 \%$ of the responses were obtained within 36 hours. The annual cost of a version of the software providing unlimited responses was $\$ 200$.

A scenario-based survey was used to test the hypothesis that waiting line length could be used to predict customers' choice of whether to use the service employee or use the self-service kiosk for hotel check-in. A $4 \times 4$ factorial design was used, with each factor referring to the number of customers in each service delivery alternative. Participants of the study read a scenario explaining that they were about to check-in in a hotel and could choose between using a self-service kiosk and using a service employee. They were given a description of the service setting, a description of the length of the waiting lines (which varied by condition) and asked which line they would choose. For example, the first scenario described the situation where no customer was waiting for either alternative and both service delivery alternatives were available. The participant could choose whether to receive service from the employee, or use the self-service kiosk without either alternative requiring him to wait. The second scenario described a customer being helped by the service employee and the self-service kiosk being available. Scenario sixteen presented the situation where both the service employee and the self-service kiosk were in use, and two customers were waiting for each alternative. The participant then indicated which line he would like to join (a binary variable).

Logistic regression, a specialized form of regression, was used. The binary dependent variable was customers' choice to use the self-service kiosk or use the service employee. The two independent variables were the number of customers waiting to use the self-service kiosk, and the number of customers waiting to use the service employee. The baseline model $-2 \log$-likelihood was 1,324.291 for the analysis sample. The introduction of the two waiting line variables reduced the -2 log-likelihood to 982.540 . The reduction was significant $\left(\chi^{\wedge}=341.751, \mathrm{p}<0.001\right)$, suggesting that the inclusion of these two variables significantly improved the predictive ability of the model. The $\mathrm{R}_{\text {LOGIT }}^{2}$ measure for this model was 0.258 . Cox \& Snell $\mathrm{R}^{2}$ was 0.291 and Nagelkerke $\mathrm{R}^{2}$ was 0.395 . The classification accuracy of the model was $76.50 \%$ for the analysis sample and $81.7 \%$ for the holdout sample. Taken together, these results indicate the assumption that waiting line length can be used to predict customer choice of a service delivery alternative holds.

The logistic coefficients obtained (shown in Table 1) were used to compute the probability that a customer would select the self-service technology $P(S S)$ alternative based on the number of individuals waiting for self-service (including the one currently using the self-service kiosk) $\left(\mathrm{x}_{1}\right)$ and the number of individuals waiting for service by a service employee (including the one currently talking with the service employee) $\left(\mathrm{x}_{2}\right)$ such that $\mathrm{P}(\mathrm{SS})=1 /\left(1+\mathrm{e}^{-(-1.094-0.836 \times 1+1.087 \times 2)}\right)$. This probability was used in the simulation model.

\section{SIMULATION STUDY}

A simulation study was conducted to examine the impact that adding a self-service kiosk to a hotel checkin process manned by three employees would have on customer waiting times. A simulation model was formulated using information collected from observing the system (customer inter-arrival times and service employee processing times), from secondary data sources (self-service kiosk processing times and 


\section{Kokkinou and Cranage}

failure rates), and from the scenario based survey (probability that customers would use the self-service kiosk). The simulation model was developed using an academic version of ARENA 12 (Rathmell and Sturrock 2002).

Table 1: Logistic Regression Coefficients

\begin{tabular}{|c|c|c|c|c|c|c|c|c|}
\hline & \multirow{2}{*}{ B } & \multirow{2}{*}{ S.E. } & \multirow{2}{*}{ Wald } & \multirow{2}{*}{ df } & \multirow{2}{*}{ Sig. } & \multirow{2}{*}{$\operatorname{Exp}(B)$} & \multicolumn{2}{|c|}{$\begin{array}{l}\text { 95\% C.I.for } \\
\text { EXP(B) }\end{array}$} \\
\hline & & & & & & & Lower & Upper \\
\hline PAX & 1.087 & .082 & 174.580 & 1 & $<.001$ & 2.967 & 2.525 & 3.486 \\
\hline SST & -.836 & .078 & 116.232 & 1 & $<.001$ & .433 & .372 & .505 \\
\hline Constant & -1.094 & .165 & 43.872 & 1 & $<.001$ & .335 & & \\
\hline
\end{tabular}

Customers' decision of whether to use a service employee or use a self-service kiosk was modeled using a Decision Module. The ARENA expression was

$100 /(1+\mathrm{EP}(-(-1.09445133-0.83611324 *(\mathrm{NR}(\mathrm{SST})+\mathrm{NQ}($ Seize

SST. Queue $))+1.08745863 *(\mathrm{MX}(0, \mathrm{NR}($ Employee $)-$

MR (Employee) +1) +AINT (NQ (Sei zeEmployee.Queue) /MR (Employee)))))) )

Where $N R(S S T)$ is the number of self-service kiosks currently in use, $N Q$ (Seize SST.Queue) is the number of individuals waiting for the self-service kiosk, NR(Employee) is the number of service employees currently busy, MR(Employee) is the total number of service employees, and NQ(Seize Employee.Queue) is the number of individuals waiting for service by the service employee(s). AINT is a truncation formula.

A sensitivity analysis was conducted to examine which assumptions the model could be sensitive to. We examined the impact that jockeying had on the model results and found it to be not significant. Similarly, we examined whether an error in estimating the probability that customers would select the selfservice technology alternative $(P(S S))$ would impact the results. We found that a deviation of $10 \%$ did not have an impact on the results. We did find that, under high utilization conditions, the results were sensitive to assumptions about the failure rate of the self-service kiosk and the processing time of the selfservice kiosk.

Based on these findings, the failure rate of the self-service kiosk, the arrival rate of customers and the processing time of the self-service kiosk were varied to reflect operational uncertainty. We assumed decision makers had discretion over the number of service employees and the number of self-service kiosks to be implemented, and that jockeying was possible. This resulted in a 2 (number of self-service kiosks) x 3 (number of service employees) x 3 (arrival rate) x 2 (failure rate of self-service kiosk) x 3 (processing time of self-service kiosks) experimental design, yielding 108 simulation models. Analysis of variance showed that all of these factors had the potential to impact significantly the results of the simulation. However, waiting times and service level were influenced most (as measured by $\eta^{\wedge}$ ) by the number of resources available (self-service kiosk and service employees). Specifically, under the observed demand conditions, there was sufficient capacity to meet demand, and adding a self-service kiosk to the check-in process manned by three employees did not reduce waiting time. Under very high demand conditions (42\% higher than observed), adding a self-service kiosk to the process decreased waiting times significantly, as long as the self-service kiosk had an average processing time close to industry norms.

\section{CONCLUSION}

The success of the simulation study described relied heavily on the precision with which customers' decision of whether to use the self-service technology or use the service employee could be modeled. Previous research on this topic was quick and inexpensive to access, yet it did not allow for accurate modeling as the self-service technologies and contexts in which the research was conducted were different from the 


\section{Kokkinou and Cranage}

context of this particular study. Primary data collection is typically considered to be expensive and slow. However, by using an online survey design and administration tool we kept it inexpensive and relatively fast. Combining the use of primary data collection, in the form of scenario-based surveys, with previous research on the topic, also allowed us to quickly identify relevant variables, further reducing the total time needed for the study.

As this example shows, for simulations involving customer service-based processes, in which human behavior plays an important role, modelers should consider combining previous theories with relatively inexpensive and fast data collection methods for those model components that have a large impact on the model's results and hence the business decision to be made.

\section{ACKNOWLEDGMENTS}

We would like to acknowledge funding provided by the Harrah Research Endowment.

\section{REFERENCES}

Baker J., and M. Cameron. 1996. "The Effects of the Service Environment on Affect and Consumer Perceptions of Waiting Time: an Integrative Review and Research Propositions." Journal of the Academy of Marketing Science 24:338-349

Bateson, J. E. G. 1985. "Self-service Consumer: An exploratory study.” Journal of Retailing 61:49-76.

Berry, L. L. 1999. Discovering the Soul of Service. New York: Free Press.

Bitner, M. 1990. "Evaluating Service Encounters: The Effects of Physical Surroundings and Employee Responses." The Journal of Marketing 54: 69-82.

Chase, R. B. 2010. 'Revisiting: 'Where Does the Customer Fit in a Service Operation?' Background and Development of Future Theory." In Handbook of Service Science: Research and Innovations in the Service Economy, edited by P.P. Maglio, C. Kieliszewski, and J. Spohrer, 11-17. New York: Springer.

Curran, J. M., and M. L. Meuter. 2007. "Encouraging Existing Customers to Switch to Self-Service Technologies: Put a Little Fun in Their Lives." Journal of Marketing Theory and Practice 15:283298.

Curran, J. M., M. L. Meuter, and C. F. Surprenant. 2003. "Intentions to Use Self-Service Technologies: A Confluence of Multiple Attitudes." Journal of Service Research 5:209-224.

Dabholkar, P. A. 1994. "Incorporating Choice into an Attitudinal Framework: Analyzing Models of Mental Comparison Processes.” Journal of Consumer Research 21:100 - 118.

Dabholkar, P. A. 1996. "Consumer Evaluations of New Technology-Based Self-Service Options: An Investigation of Alternative Models of Service Quality." International Journal of Research in Marketing 13:29-51.

Dabholkar, P. A., and R. P. Bagozzi. 2002. "An Attitudinal Model of Technology Based Self Service: Moderating Effects of Consumer Traits and Situational Factors." Journal of the Academy of Marketing Science 30:184 - 201.

Dickson, D., R. C. Ford, and B. Laval. 2005. "Managing Real and Virtual Waits in Hospitality and Service Organizations." Cornell Hotel and Restaurant Administration Quarterly 46:52-68.

Hueter, J., and W. Swart. 1998. “An Integrated Labor-Management System for Taco Bell.” Interfaces 28: 75-91.

Kumar, P., M. Kalwani, and M. Dada. 1997. “The Impact of Waiting Time Guarantees on Customers' Waiting Experiences.” Marketing Science 16:295-314.

Mayock, P., 2010. "Checking in on self-service kiosks." HotelNewsNow Accessed June 29, 2010. http://www.hotelnewsnow.com/Articles.aspx/2652/Checking-in-on-self-service-kiosks. 


\section{Kokkinou and Cranage}

Meuter, M. L., M. J. Bitner, A. L. Ostrom, and S. W. Brown. 2005. "Choosing Among Alternative Service Delivery Modes: an Investigation of Customer Trial of Self Service Technologies." Journal of Marketing 69:61 - 83.

Meuter, M. L., A. L. Ostrom, M. J. Bitner, and R. I. Roundtree. 2003. "The Influence of Technology Anxiety on Consumer Use and Experiences with Self Service Technology." Journal of Business Research 56:899 - 906.

Meuter, M. L., A. L. Ostrom, R. I. Roundtree, and M. J. Bitner. 2000. "Self-Service Technologies: Understanding Customer Satisfaction with Technology-Based Service Encounters." Journal of Marketing 54: 50 - 64.

Oh, H., and M. Jeong. 2009. "A Self-Service Technology Adoption Model in the Resort Hotel Environment." In Proceedings of the 2009 International-CHRIE Conference, edited by E. Christou, 1-8. Amherst, Massachusetts: Scholarworks at University of Massachusetts

Rathmell, J., and D. T. Sturrock. 2002. "The Arena Product Family: Enterprise Modeling Solutions." In Proceedings of the 2002 Winter Simulation Conference, edited by E. Yücesan, C.-H. Chen, J. L. Snowdon, and J. M. Charnes, 165-172. Piscataway, New Jersey: Institute of Electrical and Electronics Engineers, Inc.

Seawright, K. K., and S. E. Sampson. 2007. "A Video Method for Empirically Studying Wait-Perception Bias.” Journal of Operations Management 25:1055 - 1066.

Starks, D. W., and T. C. Whyte 1998. "Tutorial: Simulation in the Hospitality Industry." In Proceedings of the 1998 Winter Simulation Conference, edited by D.J. Medeiros, E.F. Watson, J.S. Carson and M.S. Manivannan, 37-39. Piscataway, New Jersey: Institute of Electrical and Electronics Engineers, Inc.

Sterman, J. D. 1987. “Testing Behavioral Simulation Models by Direct Experiment." Management Science 33:1572-1592.

Tumay, K. 1995. "Business Process Simulation." In Proceedings of the 1995 Winter Simulation Conference, edited by C. Alexopoulos, K. Kang, W. R. Lilegdon, and D. Goldsman, 50-60. Piscataway, New Jersey: Institute of Electrical and Electronics Engineers, Inc.

van Beuningen, J., K. de Ruyter, M. Wetzels, and S. Streukens. 2009. "Customer Self-Efficacy in SelfService Technology: Assessing Between-and Within-Person Differences." Journal of Service Research 11:407-428.

Weijters, B., D. Rangarajan, T. Falk, and N. Schillewaert. 2007. "Determinants and Outcomes of Customers' Use of Self-Service Technology in a Retail Setting." Journal of Service Research 10:3-21.

Wemmerlöv, U. 1990. "A Taxonomy for Service Processes and its Implications for Service Design." International Journal of Service Industry Management 1:20-40.

\section{AUTHOR BIOGRAPHIES}

ALINDA KOKKINOU is a Lecturer in Hotel Management at the NHTV Breda University of Applied Sciences in the Netherlands. She received a bachelor in hotel administration from Hotelschool The Hague, an M.B.A. in Hospitality Management from IMHI, France, and a Ph.D. from the Pennsylvania State University. Her research interests include service operations management with an emphasis on hospitality service systems and the role of (customer) self-service. She also is interested in research methodologies for the hospitality industry. Her e-mail is Kokkinou.A@nhtv.nl.

DAVID A. CRANAGE is an Associate Professor in the School of Hospitality Management, The Pennsylvania State University. He received a bachelor of science in foodservice and housing administration, an M.B.A., and a Ph.D. from the Pennsylvania State University. He is the editor of the Journal of Foodservice Business Research. His research interests include pre-emptive strategies to buffer the effects of service failures and increase customer loyalty, empowerment, and informed choice. His e-mail is dac2@psu.edu. 